\title{
Soil Hydrology of Agricultural Landscapes: Quantitative Description, Research Methods, and Availability of Soil Water
}

\author{
Ye. V. Shein ${ }^{a, b, c, *}$, A. G. Bolotov ${ }^{b, c}$, and A. V. Dembovetskii ${ }^{a}$ \\ ${ }^{a}$ Lomonosov Moscow State University, Leninskie gory 1, Moscow, 119991 Russia \\ ${ }^{b}$ Dokuchaev Soil Science Institute, per. Pyzhevskii 7, Moscow, 119017 Russia \\ ${ }^{c}$ Upper Volga Federal Agrarian Research Center, \\ ul. Tsentral'naya 3, pos. Novyi, Suzdal, Vladimir oblast, 601261 Russia \\ *e-mail: evgeny.shein@gmail.com \\ Received February 2, 2021; revised February 16, 2021; accepted April 7, 2021
}

\begin{abstract}
Soil hydrology has deep Russian roots, which are primarily related to the theory of soil hydrological constants and their practical application. These constants have been used to assess the hydrological soil conditions in stationary observations, for which attempts to arrange regular hydrological observations in the landscape faced impracticable complexity of work and calculations and provided unreliable quantitative predictions. At present, there are new opportunities for experimental research, digital analysis, and prediction of hydrological indicators of soils in the landscape. A new quantitative approach to the use of digital technologies for monitoring soil water and temperature in the soils of agricultural landscapes, their dynamics, and their probabilistic calculations has been developed. Based on the soil map, it is proposed to create an information and measurement system with the studied thermal and hydrophysical characteristics of soils using mathematical models to calculate the dynamics of moisture and temperature for given periods and conditions of different availability of heat and precipitation, which allows us to quantify the availability of moisture reserves in the soils of the agricultural landscape. This system of observations, assessment, and forecast includes the use of modern technologies for determining soil water content and temperature, the adaptation of predictive physically based models for calculating the dynamics of moisture reserves depending on the availability of precipitation and conditions at the lower boundary of soil profiles. The paper deals with the hydrological analysis of soils by the example of the agricultural landscape of the Zelenograd station of the Dokuchaev Soil Science Institute in the village of El'digino, Pushkino district, Moscow oblast.
\end{abstract}

Keywords: soil water regime, thermal regime of soils, prediction, predicting, hydrophysics, physically based models, hydrothermal characteristics, soddy-podzolic soils, Albic Glossic Retisols (Loamic, Cutanic)

DOI: $10.1134 / \mathrm{S} 1064229321090076$

\section{INTRODUCTION}

Russian soil science and soil hydrology emerged almost simultaneously owing to the works of V.V. Dokuchaev aimed at combating catastrophic droughts in Russia at the end of the 19th century. Dokuchaev proposed a classical method of drought control by retaining and preserving moisture primarily on interfluves and creation of ponds and various water reservoirs in the catchments. Fortunately, in the famous Dokuchaev steppe expedition of that time, G.N. Vysotsky, G.F. Morozov, G.I. Tanfiliev, P.V. Ototsky, and other scientists worked together with him. Owing to their works, the main classical statement of soil hydrology was formulated: the need to study the behavior of soil water, its migration, accumulation, and expenditure in relation to the particular landscape elements, soils, and vegetation. This position remains the fundamental basis of soil hydrology, including the soil hydrology of modern agricultural landscapes [4, 6]. The works of
Russian and foreign hydrologists have justified the hydrological criteria that form the basis for the quantitative assessment of the state of soil water, its movement, and its availability for plants, or the so-called soil-hydrological constants: field water capacity (FWC), capillary rupture moisture (CRM), and wilting point (WO). These constants and methods of their determination are still used by soil hydrologists to assess the water content and water movement in soils and are widely applied in soil reclamation projects and management of agricultural landscapes.

It should be noted that during hydrological studies in landscapes, hydrologists have faced a number of problems, the solution of which will now allow soil hydrology and thermal physics to reach a new level of studying, analyzing, and predicting thermal and water phenomena in the soils of agricultural landscapes [2, 13]. These problems are related to (1) the diversity of soils of different textures and, hence, with different hydro- 
logical and thermal properties, in agricultural landscapes; (2) the variability in the level and composition of soil and groundwater; (3) the presence of drainage positions in the landscape; (4) the need to conduct observations at stationary points for a sufficiently long time capturing periods with dry and wet years; and (5) the need to conduct long-term studies of soil water in the landscape, i.e., to take soil auger samples from different depths at the same points, which is even theoretically impossible with the drilling method. Foreign hydrology has found a temporary theoretical and experimental way out of this situation by introducing the concept of soil as a heterogeneous polydisperse natural medium with upper and lower hydrological boundaries, between which the movement of water in the soil occurs naturally in accordance with Darcy's Law and Richard's equation [5, 7-9], which allowed the development of mathematical descriptive models. This approach has recently been supplemented by statistical characteristics of the water distribution in the soil cover within a framework of a new scientific areahydropedology [16, 19-21, 27]. Certainly, this model approach cannot fully and adequately describe the hydrological state of soils in agricultural landscapes because of its determinism, the need to justify and take into account pedotransfer functions, which do not always have a physical justification, but contain only a statistical core, to some extent allowing us to reflect the hydrological and fundamental physical properties of the soil. A challenge is to clearly adapt the models for specific conditions $[3,25,30]$.

There are also difficulties in describing connections between groundwater and soil water, especially in the case of hydromorphic soils, as well as in the assessment of the spatial variability of the hydrophysical properties of soils and conditions at the boundaries. These reasons led to the need to reorganize the theoretical, experimental, and computational work on soil hydrology and thermal physics. The concepts of "unsaturated zone" and "critical zone" appeared, which are more related to the environmental problems of the movement of pollutants from the unsaturated zone to the groundwater. However, at the same time, the natural-historical aspect and genetic features of the formation and development of landscapes were less taken into account; simplified models with linear relationships were used, and other assumptions were made for the possibility of real and predictive calculations [22, 24].

A practical comprehensive solution to the five problems listed above will create the prerequisites for a new step in the hydrological research of soils: the development of soil-agrolandscape hydrology (in this paper, we will not consider the thermophysical area, however, the principles of consideration for the hydrology and thermal physics of soils of agrolandscapes are identical). Currently, we can have all the components of soil-agrolandscape hydrological research: the scientific theory of agrolandscape zoning using soil-landscape and agrochemical maps, state-of-theart hydrological parameters for assessing moisture reserves in various layers of agricultural soils, digital devices for obtaining dynamic information about soil moisture and temperature, dynamic physically based models of moisture movement in the agrolandscape, statistical models for analyzing and predicting hydrological characteristics in space and time $[16,17,28]$.

The purpose of the paper is to develop a soilhydrological complex of agro-landscape studies that fully meet the requirements of modern quantitative hydrology. The issues of the work reflect the five components of soil and landscape hydrology mentioned above: (1) consideration of soil-plant and lithological diversity; (2) consideration of the diversity of hydrological conditions, including the groundwater level (GWL); (3) consideration of drainage positions in the landscape; (4) studies of long periods of time, including years (periods) with insufficient and high precipitation; and (5) the need for spatial work to determine soil water contents at specific stationary points of the agricultural landscape.

\section{OBJECTS AND METHODS}

The tasks set should be solved step by step. As a simple and understandable example, we will consider all the marked steps for a particular landscape of the experimental field of the Zelenograd station of the Dokuchaev Soil Science Institute near the village of El'digino in Pushkino district of Moscow oblast. A schematic representation of the experimental field is shown in Fig. 1. The topographic map was constructed based on the data of the levelling survey made in 2012, and all the topographic maps and topoisoplethes of water reserves provided in this paper were made in the Surfer software using the kriging interpolation method.

The soil cover of the experimental field is represented by clay loamy agrosoddy-podzolic soils of different degrees of gleyzation on the clay loam underlain at a depth of $2-3 \mathrm{~m}$ by a noncalcareous moraine (according to the WRB classification of 2014 (version of 2015), these soils are Albic Glossic Retisols (Lomic, Aric, Cutanic)).

In 1968-1969, deep plowing was carried out on the field to reduce the surface stagnation of moisture. Traces of deep plowing have survived to the present day. Morphological investigations have shown that within the field there are soils of different depths of podzolization (from 30 to $40-50 \mathrm{~cm}$ ), but due to deep plowing, a larger part of the podzolized (eluvial) horizon is involved in the plow layer. The experimental field has a slope of about $0.017^{\circ}$; in the upper part of the field, groundwater is present at a depth of about $10 \mathrm{~m}$; in the lower part, it rises to $1.5 \mathrm{~m}$ from the surface and even higher in wet years. Therefore, agrosoddy-podzolic soils are common on the larger terri- 


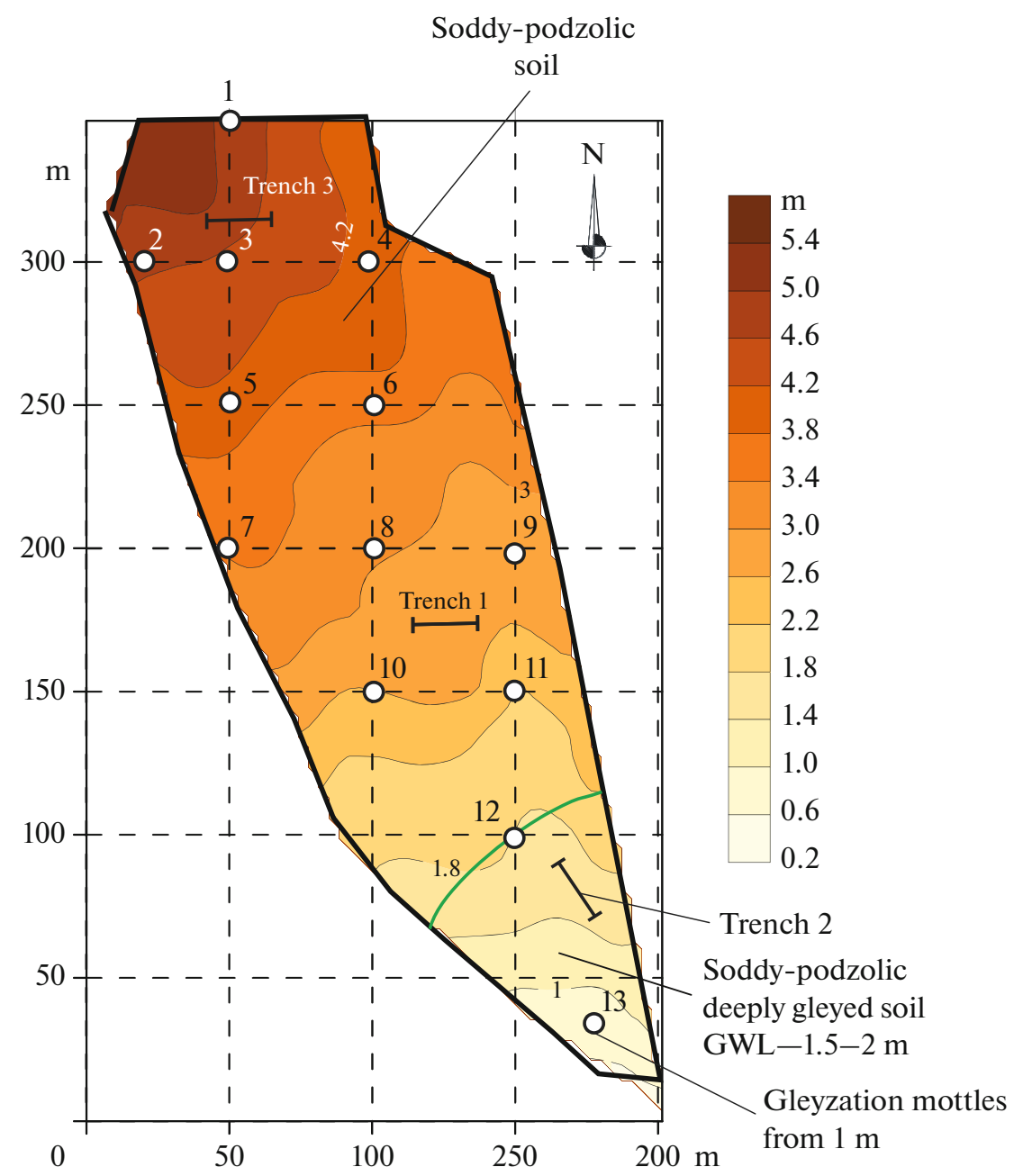

Fig. 1. Map-diagram of the position of the calculation points (1-13) and trenches $1-3$ on the experimental field of the Zelenograd station of the Dokuchaev Soil Science Institute (El'digino village) and the surface topography in the form of contour lines of relative heights. The green line on the diagram separates the soddy-podzolic soils from the soddy-podzolic deeply gleyed soils with a water table of about $2 \mathrm{~m}$ in the average precipitation year.

tory of the area; in the middle and lower parts of the field, where the groundwater level rises, agrosoddypodzolic deep-gleyed soils are widespread [10,11]. A brief morphological description of the soil profile of the experimental field in its central part (trench 1) is presented below. The horizons were indexed according to the Russian soil classification of 2004 [8]. The profile has the following horizonation: $\mathrm{P} 1(0-10 \mathrm{~cm})$, P2 (10-20(25) cm), P3 (20(25)-30(40) cm), EL (30$35(40) \mathrm{cm})$, BEL $(30(40)-40(50) \mathrm{cm})$, BT1 (40(50)60(65) cm), BT2 $(60-90 \mathrm{~cm})$, BT3 $(90-130 \mathrm{~cm})$, $\mathrm{BC}-\mathrm{C}(130-200 \mathrm{~cm})$.

Note that the physical properties of these soils were studied in detail in three trenches: trench 1 (in 20112012), trench 2 (in 2013-2014), and trench 3 (20132016). The sampling points along the trenches were made at depths of $0,10,20,40$, and $60 \mathrm{~cm}$ with a horizontal step of $25 \mathrm{~cm}$. Figure 2 shows the results of soil bulk density determination along the trenches; it can be seen that it varies considerably over the entire $20 \mathrm{~m}$.
At the same time, the soil bulk density in the upper layer $(0-20 \mathrm{~cm})$ is about $1.4 \mathrm{~g} / \mathrm{cm}^{3}$, which is very important for subsequent calculations and classification of moisture reserves in these soils.

Soil-hydrological studies were carried out on the specified experimental area, which confirmed the existence of certain hydrological allotments in this area in different years according to the availability of precipitation.

The following methods were used in stationary regime observations, in particular, when conducting soil-melioration (flooding) experiments. The layerby-layer measurement of the water pressure was made by a digital tensiometer (Blumat Digital Proplus, Austria) consisting of a ceramic stand, a measuring unit with a display, and a power battery [14]. The device has a control button that allows one to turn it on and select the units of measurement. The device turns off automatically. This tensiometer is a convenient 


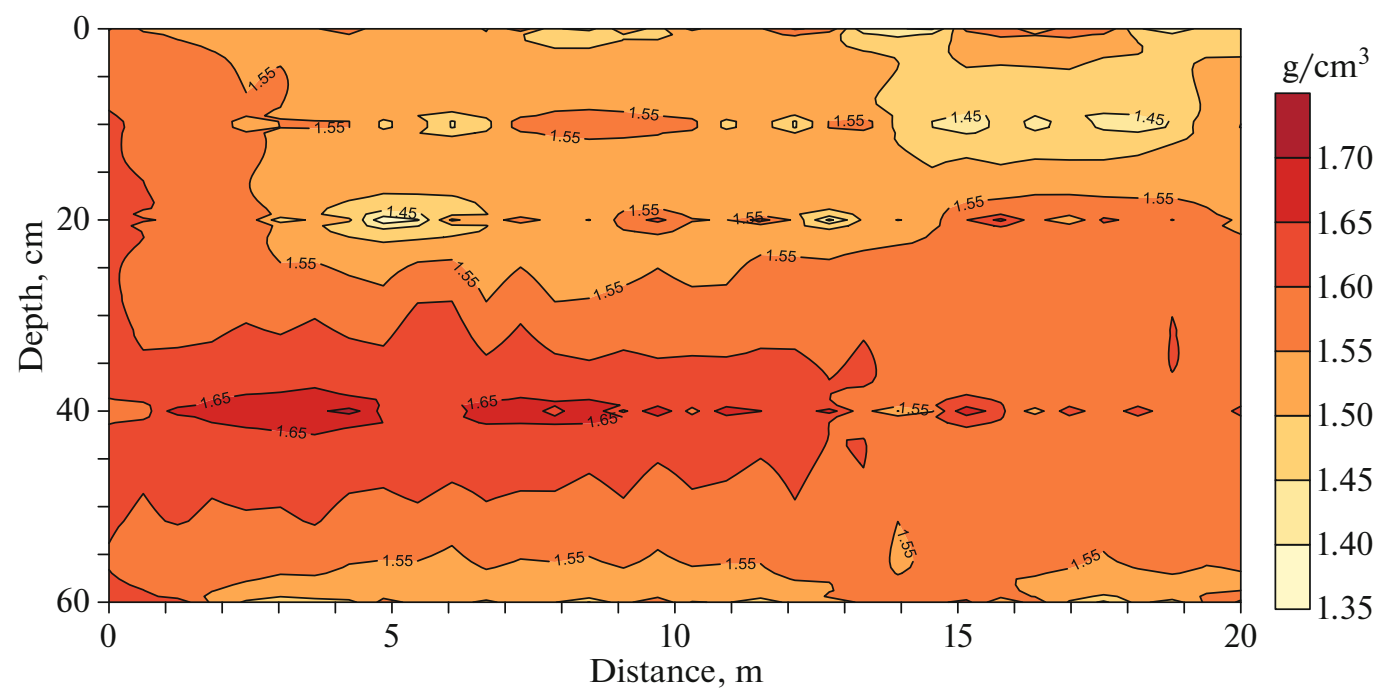

Fig. 2. Topoisopleths of the bulk density of agrosoddy-podzolic soil along the 20 -m-long trench 1.

device for field measurements. The pressure measurement range is $10-750 \mathrm{mbar}$, or approximately from 0.01 to $0.75 \mathrm{~atm}$, or from 10 to $770 \mathrm{~cm}$ of the water column, that is, it can be assumed that the tensiometer of such a construction presents data in $\mathrm{cm}$ of the water column. The length of the working part inserted into the soil is $18 \mathrm{~cm}$. To study the distribution of water pressure along the soil profile, the tensiometer was modified into a device with an elongated working part, into which a vacuum plastic hose was inserted. The soil water content was measured by Decagon Teros 12 sensors, which allow measuring the values of the dielectric constant, which, according to the calibration correlation given in [29], are transformed into the soil water content values displayed on the recorder screen.

\section{RESULTS AND DISCUSSION}

At the first stage of soil-hydrological agrolandscape studies, in accordance with the system of land assessment and typology and the landscape-ecological classification set out in the methodological guide [8], it is necessary to use a soil map with accurate allocation of land categories within the studied agrolandscape [1].

A diagram of observation points (13 points) for soil-hydrological studies is shown in Fig. 1, which allows us to make sufficiently detailed soil-hydrological allotments in the specified landscape in years with different precipitation. The drainage position in the landscape was located beyond the studied area. $50 \mathrm{~m}$ from point 13 , where the territory was drained by a ravine, which in wet years had a temporary water flow. Thus, we have very briefly described issues $1-3$ of this work as the constituent stages of soil and landscape hydrological surveys.

The next issue of the work is to conduct research over long periods, considering years with insufficient and high availability of precipitation. This is a very important task aimed at assessing the probability of occurrence of adverse conditions, that is, to assess the risk of catastrophic soil and hydrological situations. At the same time, it is the most complex in technical terms, as it involves the use of digital technologies and predictive mathematical models.

It is quite clear that to study the stationary water regime, to determine the moisture reserves in the required mass of the soil at all the observation points (13 points. Fig. 1) in years with different moisture availability (if necessary, heat supply) is very difficult, time-consuming and, thus, unacceptable for rapidly developing agrolandscape farming. Therefore, the following approach was proposed, including conducting soil-melioration (flooding) experiments at the main stationary points (in this case, near trenches 1-3). At these stationary points, in special core samples with a diameter of $60 \mathrm{~cm}$ and a depth of up to $1 \mathrm{~m}$, equipped with devices for continuous observations of the water content, soil water pressure, and soil temperature, conditions were created in layers from complete saturation due to artificial flooding to subsequent drying within 5-10 days. The results of the layer-by-layer water pressure measurements by tensiometers are shown in Fig. 3.

Synchronous observations of water pressure and soil water content when monitoring meteorological conditions in the surface air layer that determine evapotranspiration make it possible to adapt a physically based model of water movement in the soil [12, $15,26]$. In other words, to adjust the model so that it gives the lowest error in the values of water content and water pressure in the stationary experiment. This setting of the model with the corresponding error in determining water content and water pressure provides the basis for its use within the studied agricultural landscape for analogous soil and landscape condi- 
tions. Therefore, the HYDRUS model configured for soil flooding experiments in the area of trenches 1 and 3 was used for predictive calculations of soil moisture dynamics at points $1-10$, and the specified flooding experiment at trench 3 was used for points 11-13.

It should be noted that there were no fundamental differences in the hydrophysical properties of the soils at the stationary points near trenches 3 and 2. Significant differences were only related to the setting of conditions at the lower boundary of the soil profile (in trenches 1 and 3, free outflow of water; in trench 2 , close groundwater table). After the model was set up for specific soil and landscape conditions, we tried to make a long-term forecast of the hydrological behavior of the landscape at points $1-13$ for the years with different precipitation supply and, hence, years with different moisture reserves. In this case, the hydrological concept of water availability was used as a characteristic of moisture reserves in the years of different availability of precipitation. In hydrology and soil reclamation (calculations of precipitation, temperature, drainage runoff, spring and autumn floods, etc.), a probabilistic approach is used based on determining the probability of a particular characteristic. Water supply is understood as the probability of occurrence (\%) of a value equal to or greater than that given in a multiyear series. For example, $90 \%$ precipitation probability means that in $90 \%$ of cases this amount of precipitation can be exceeded [6]. It should be noted that in the Pushkino district of Moscow Oblast, the precipitation during the growing season (May-September) varies from 180 to $95 \mathrm{~mm}$, which corresponds to the precipitation probability from 25 to $90 \%$. At the same time, the availability of moisture reserves in the $20-\mathrm{cm}$-soil layer according to our five-year observations and special experiments varied from 82 to $35 \mathrm{~mm}$, which corresponded to the probability range from 25 to $90 \%$. These curves of precipitation supply and moisture reserves in the 20-cm-thick soil layer during the growing season (May-September) are shown in Figs. $4 \mathrm{a}$ and $4 \mathrm{~b}$.

Why is it necessary to use the probability of soil moisture reserves instead of the traditional value of moisture reserve, in order to characterize the hydrology of soils in the agricultural landscape? The fact is that moisture reserves are extremely dynamic. During rainfall, moisture reserves change dramatically in the agrosoils of the landscape. Therefore, it is difficult to use these data for projecting, long-term evaluation, and finding the optimal solution in agricultural production. Obviously, as a real characteristic in real production time, the values of moisture reserves along with the soil hydrological constants should and will be used for agricultural landscapes [4, 6, 7]. However, for the sustainable and long-term characterization, evaluation, analysis, and development of agricultural systems, along with the current moisture reserves, we recommend using the value of the moisture reserves probability, indicating the soil layer and the period for which this probability is calculated. Current moisture

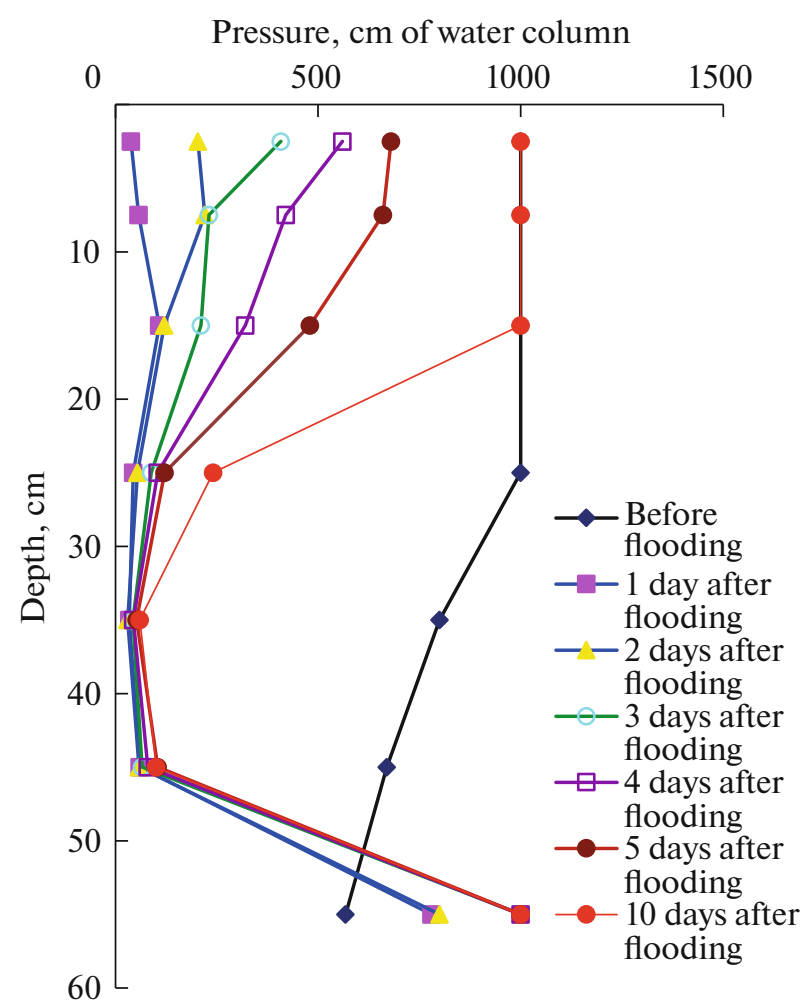

Fig. 3. Profile distribution of moisture pressure (by tensiometers) in arable agrosoddy-podzolic soil (field experiment on soil flooding).

reserves in various soil layers are important for operational management, and probability values are necessary for long-term assessment and predicting possible significant catastrophic changes in the water regime of soils. Apparently, both characteristics with their purposeful combination are able to give long-term and real dynamic estimates and predict changes and forecasts of the water regime of the soils of agricultural landscapes.

Let us consider the calculation of the precipitation probability curve. The moisture availability curve for the layer of $0-20 \mathrm{~cm}$ was obtained by calculations using the predictive HYDRUS model for the growing season (May-September) setting the precipitation probability from 25 to $90 \%$ for automorphic conditions and averaging the hydrophysical properties of soils in this layer. The resulting moisture supply curve is shown in Fig. $4 \mathrm{~b}$ for points $1-13$ at $50 \%$ probability. For each point $(1-13)$, the availability of moisture reserves was calculated taking into account the hydrophysical properties of the soil and the conditions at the lower boundary. For most of the field, the lower boundary condition is free outflow, and for the lower part (points 11-13), the GWL was set within the range from 1.5 to $4 \mathrm{~m}$. The upper boundary condition is the same for all calculated points. Therefore, in this example of calculating the availability of moisture in the 
(a)

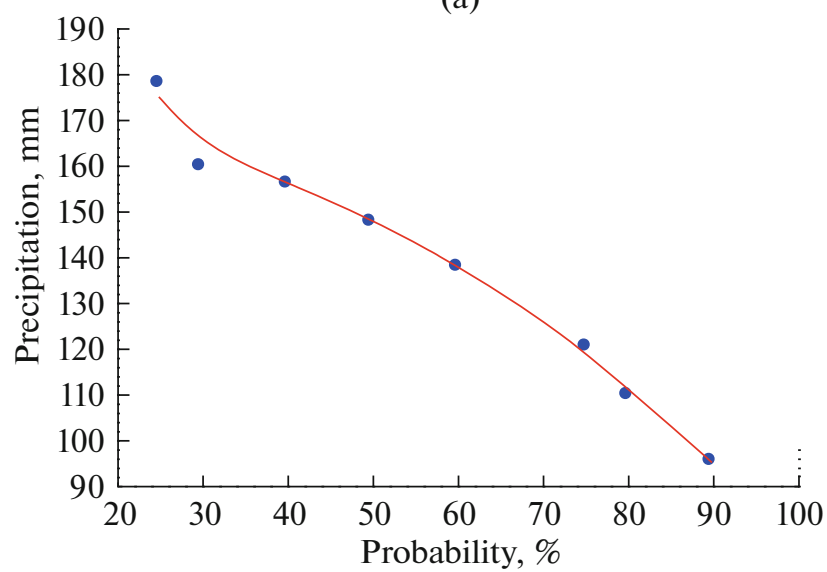

(b)

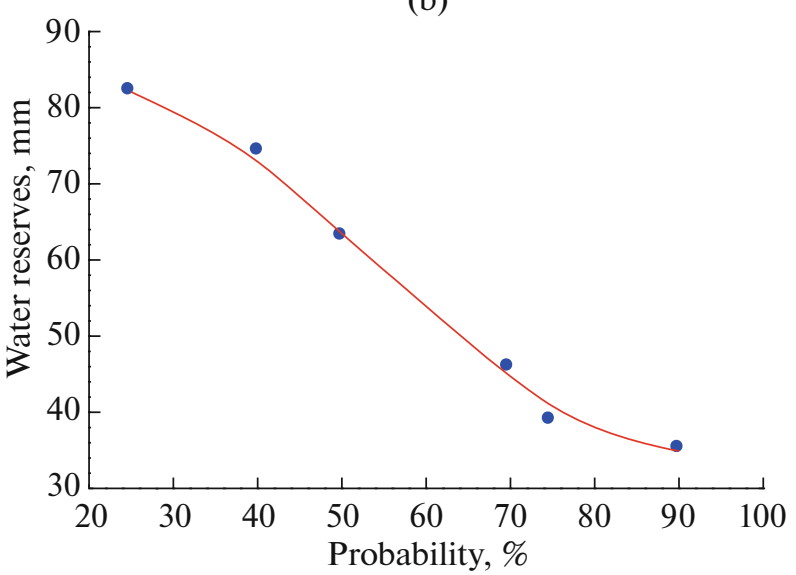

Fig. 4. Probability of (a) precipitation in Pushkino (from the Internet) and (b) moisture reserves in the layer of $0-20 \mathrm{~cm}$ of the agrosoddy-podzolic soil (El'digino) for the period from May to September.

(a)

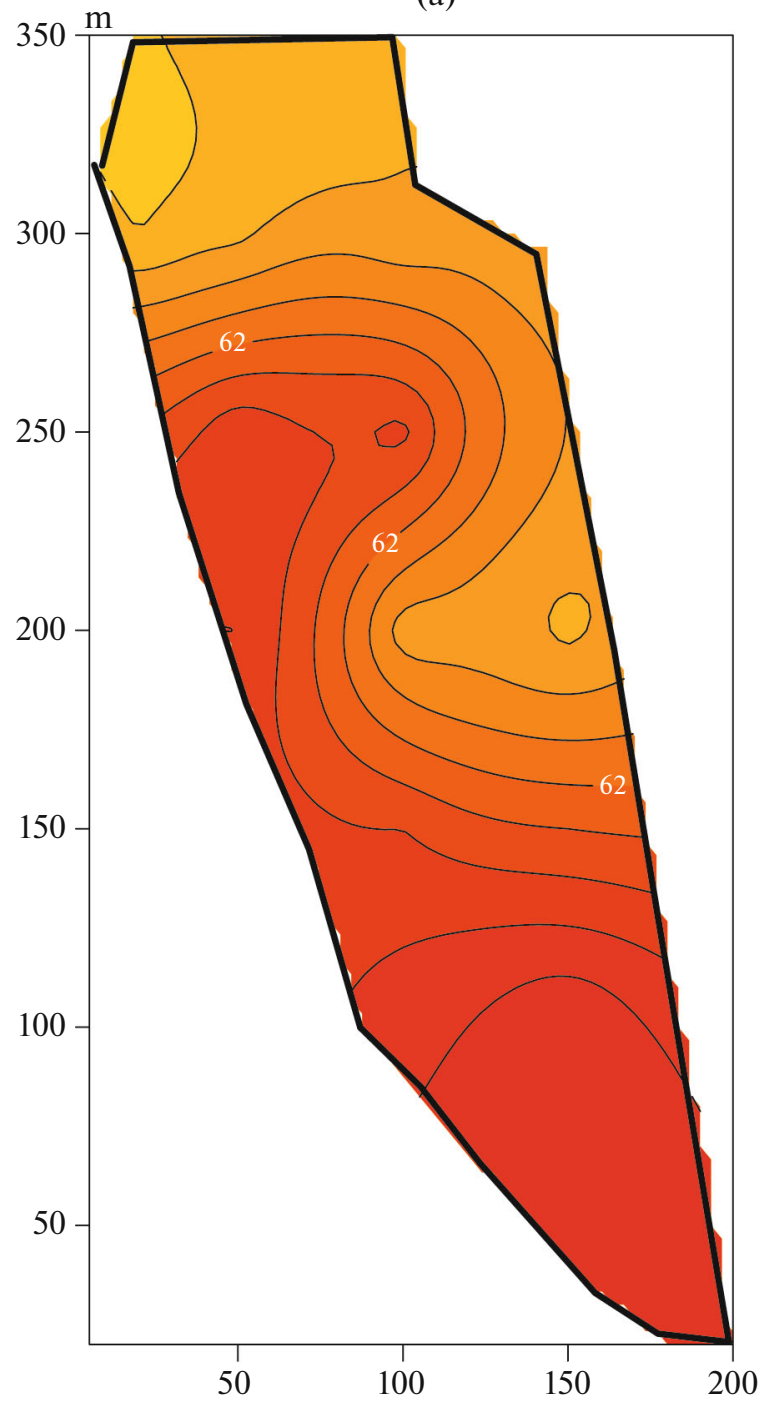

(b)

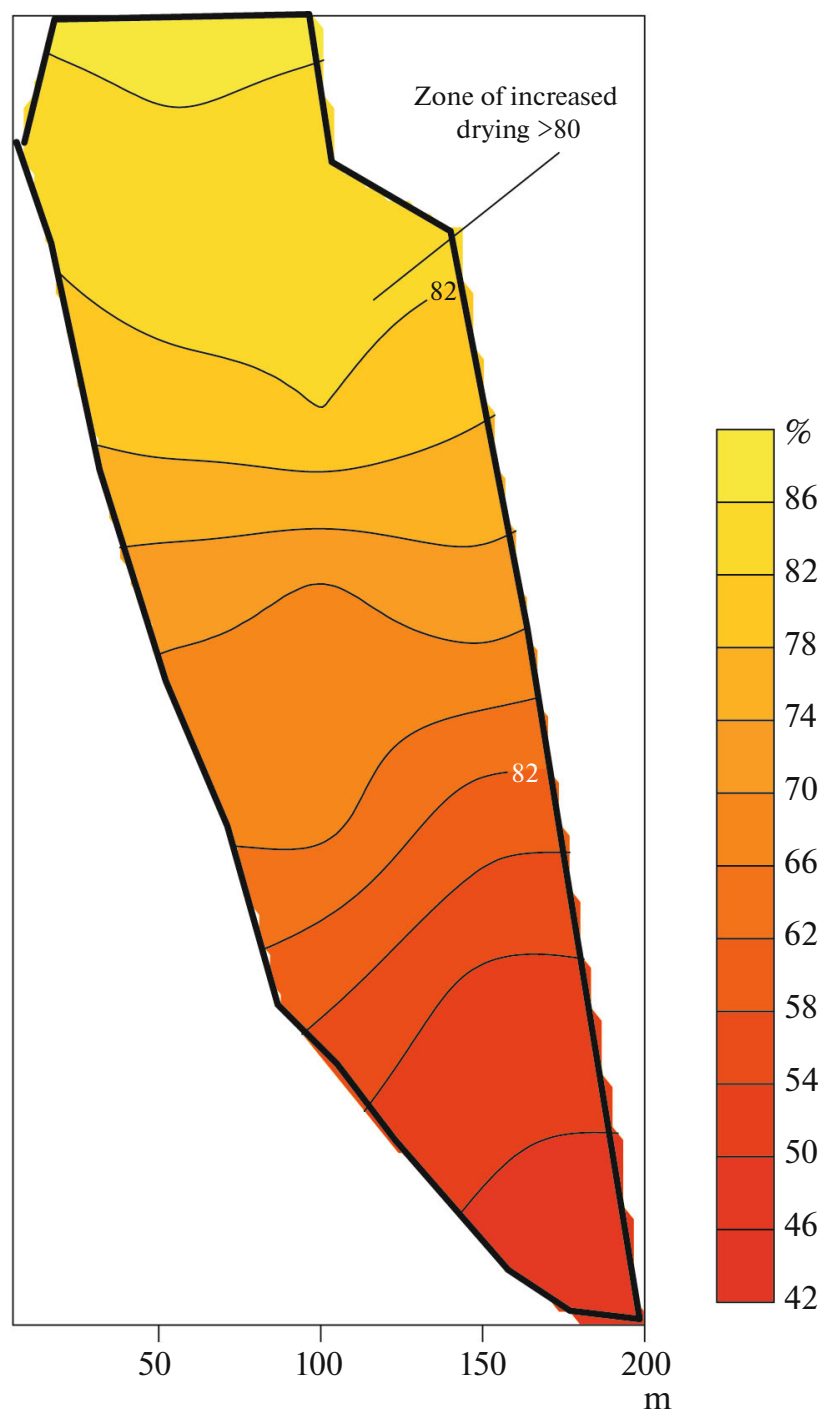

Fig. 5. Soil moisture reserves in the agrosoil at (a) $50 \%$ and (b) $75 \%$ probability of precipitation during the growing season (MaySeptember). 
upper $20 \mathrm{~cm}$ during the growing season, the variable spatial factors are the hydrophysical properties of the soil, the GWL, and precipitation provision, which is included in the calculation as the upper boundary condition. (In this approach, the hydrophysical properties are first set for all points, then the water regime is considered, and the probability is estimated). In this case, the horizontal movement of water in the unsaturated soil mass is considered negligible in comparison with the vertical movement and is not taken into account in the horizontal water movement, in which the main role is played by groundwater during the period of water accumulation in the fall and in the spring snowmelt season. In this example, these processes were not included in the calculation.

As can be seen from Fig. 5, the topoisopleths of the moisture reserves in the layer of $0-50 \mathrm{~cm}$ layer for the periods of May-September differ insignificantly, but regularly. In the median year, there is a zone with deeply gleyed soils in the lower part of the field, characterized by the probability of moisture reserves of less than $50 \%$ (that is, the median water supply). In a dry year, under the condition of $75 \%$ precipitation probability, this zone, although it remains at the median level of water supply, increases significantly. Moreover, in dry years, the GWL decreases significantly, which should lead to a significant decrease in the availability of soil water in the layers of $0-50$ and $0-$ $100 \mathrm{~cm}$, which are often included in agronomic estimates and predictions. This will require additional calculations and work on their experimental support (in particular, hydrophysical functions for a layer of 50$100 \mathrm{~cm}$ should be determined). Thus, using the statistical concept of probability, it is possible to represent changes in the patterns of moisture reserves in the years of different precipitation probability as a final long-term characteristic of the hydrology of the agricultural field in the landscape.

It should be noted that the given data on the soil moisture reserves for the experimental field of the Dokuchaev Soil Science Institute are only an example of the possibility of using statistical hydrological concepts in soil hydrology, which allow us to conduct a continuous assessment of the hydrological regime of soils. The given example characterizes the availability of moisture reserves only in the thickness of $0-50 \mathrm{~cm}$ and in the period from May to September without taking into account winter precipitation and with some assumptions in the calculations. The considered approach and experimental data on the agrolandscape of the Zelenograd station of the Dokuchaev Soil Science Institute represent a central "digital image" that can be used in soil hydrology in its transition to stateof-the-art quantitative landscape approaches.

\section{CONCLUSIONS}

Using the soil-hydrological and reclamation concepts of probability, appropriate methods and experi- ments, as well as mathematically adapted models for years with different precipitation probability, an approach is justified and an experimental picture of the moisture reserves in the studied agricultural landscape is presented. Isopleths of the moisture reserves probability are the main document of the predicted hydrological (and temperature) conditions. This map of moisture probability isopleths is the basis for analyzing the hydrological situation in the agricultural landscape and identifying critical zones and periods of its hydrological functioning. It can be used as the basis for finding optimum solutions for planning and managing water and thermal conditions of soils.

\section{FUNDING}

This study was performed within the framework of the state assignment "Physical Foundations of Ecological Functions of Soils: Technologies for Monitoring, Forecasting and Management" and partly (50\%) supported by the Russian Foundation for Basic Research, project no. 19-29-05112 mk.

\section{CONFLICT OF INTEREST}

The authors declare that they have no conflicts of interest.

\section{OPEN ACCESS}

This article is licensed under a Creative Commons Attribution 4.0 International License, which permits use, sharing, adaptation, distribution and reproduction in any medium or format, as long as you give appropriate credit to the original author(s) and the source, provide a link to the Creative Commons license, and indicate if changes were made. The images or other third party material in this article are included in the article's Creative Commons license, unless indicated otherwise in a credit line to the material. If material is not included in the article's Creative Commons license and your intended use is not permitted by statutory regulation or exceeds the permitted use, you will need to obtain permission directly from the copyright holder. To view a copy of this license, visit http://creativecommons.org/licenses/by/4.0/.

\section{REFERENCES}

1. Agroecological Assessment of Land and Planning of Adaptive-Landscape Systems of Agriculture and Agrotechnologies, Ed. by V. I. Kiryushin and A. L. Ivanov (Rosinformagrotekh, Moscow, 2005) [in Russian].

2. A. G. Bolotov, E. V. Shein, and S. V. Makarychev, "Water retention capacity of soils in the Altai region," Eurasian Soil Sci. 52, 187-192 (2019).

3. Ye. M. Gusev and L. Ya. Dzhogan, "Soil mulching as an important element in the strategy of using natural water resources in agroecosystems of the steppe Crimea," Eurasian Soil Sci. 52, 313-318 (2019).

4. F. R. Zaidel'man, Hydrological Regime of Soils in Nonchernozem Area: Genetic, Agronomic, and Meliorative Aspects (Gidrometeoizdat, Leningrad, 1985) [in Russian]. 
5. F. R. Zaidel'man, Melioration of Soils (KDU, Moscow, 2017) [in Russian].

6. F. R. Zaidel'man, L. F. Smirnova, A. P. Shvarov, and A. S. Nikiforova, Practical Manual on Lecture Course "Soil Reclamation" (Grif i K, Tula, 2008) [in Russian].

7. V. I. Kiryushin, The Development of the Concept of Landscape-Adaptive Farming in the Nonchernozemic Area (Kvadro, Moscow, 2020) [in Russian].

8. L. L. Shishov, V. D. Tonkonogov, I. I. Lebedeva, and M. I. Gerasimova, Classification and Diagnostic System of Russian Soils (Oikumena, Smolensk, 2004) [in Russian].

9. A. I. Madi and E. V. Shein, "Saturated hydraulic conductivity of soils: experimental determination and calculation using pedotransfer functions," Agrofizika, No. 1, 37-44 (2018). https://doi.org/10.25695/AGRPH.2018.01.05

10. N. A. Muromtsev and K. B. Anisimov, "Specific water regime of soddy-podzolic soil on different elements of soil catena," Byull. Pochv. Inst. im. V.V. Dokuchaeva, No. 77, 78-93 (2015).

11. N. A. Muromtsev, N. A. Semenov, and K. B. Anisimov, "Specific moisture consumption and water supply of plants from various ecological groups," Byull. Pochv. Inst. im. V.V. Dokuchaeva, No. 82, 71-87 (2016).

12. S. S. Panina and E. V. Shein, "Mathematical models of soil moisture transfer: importance of experimental assurance and upper boundary conditions," Moscow Univ. Soil Sci. Bull. 69, 133-138 (2014).

13. E. V. Shein, "Soil hydrology: stages of development, current state, and nearest prospects," Eurasian Soil Sci. 43, 158-167 (2010).

14. E. V. Shein, A. G. Bolotov, A. B. Umarova, et al., Manual for Use of Digital Sensors for Field Soil Physics Observations (KDU, Moscow, 2019) [in Russian].

15. E. V. Shein, E. B. Skvortsova, S. S. Panina, A. B. Umarova, and K. A. Romanenko, "Hydro-depositary and hydro-transmitting properties of soddy-podzolic soils in the course of simulating the water transfer by physically grounded models," Byull. Pochv. Inst. im. V.V. Dokuchaeva, No. 80, 71-82 (2015).

16. M. J. Lees, "Data-based mechanistic modeling and forecasting of hydrological systems," J. Hydroinf. 2, 15-34 (2000). https://doi.org/10.2166/hydro.2000.0003

17. Y. Li, Q. Zhang, J. Lu, J. Yao, and Z. Tan, "Assessing surface water-groundwater interactions in a complex river-floodplain wetland-isolated lake system," River Res. Appl. 35, 25-36 (2019). https://doi.org/10.1002/rra.3389

18. L. X. Liang, D. P. Lettenmaier, E. F. Wood, and S. J. Burges, "A simple hydrologically based model of land surface water and energy fluxes for GSMs," J. Geophys. Res.: Atmos. 99 (7), 14415-14428 (1994).
19. H. Lin, J. Bouma, Y. Pachepsky, A. Western, J. Thompson, R. van Genuchten, H.-J. Vogel, and A. Lilly, "Hydropedology: synergistic integration of pedology and hydrology," Water Resour. Res. 42, W05301 (2006). https://doi.org/10.1029/2005WR004085

20. H. S. Lin, "Hydropedology: towards new insights into interactive pedologic and hydrologic processes across scales," J. Hydrol. 406, 141-145 (2011). https://doi.org/10.1016/j.jhydrol.2011.05.054

21. H. S. Lin, J. Bouma, L. Wilding, et al., "Advances in hydropedology," Adv. Agron. 85, 1-89 (2005).

22. K. A. Lohse and W. E. Dietrich, "Contrasting effects of soil development on hydrological properties and flow paths," Water Resour. Res. 41, W12419 (2005). https://doi.org/10.1029/2004WR003403

23. J. J. McDonnell, M. Sivapalan, K. Vaché, et al., "Moving beyond heterogeneity and process complexity: a new vision for watershed hydrology," Water Resour. Res. 43, W07301 (2007).

24. C. Rasmussen, P. A. Troch, J. Chorover, et al., "An open system framework for integrating critical zone structure and function," Biogeochemistry 102, 15-29 (2011). https://doi.org/10.1007/s10533-010-9476-8

25. M. G. Schaap, F. J. Leij, and M. Th. van Genuchten, "ROSETTA: a computer program for estimating soil hydraulic parameters with hierarchical pedotransfer functions," J. Hydrol. 251, 163-176 (2002).

26. E. V. Shein, A. V. Dembovetsky, and S. S. Panina, "Modeling soil water movement under low head ponding and gravity infiltration using data determined with different methods," Procedia Environ. Sci. 19, 553555 (2013). https://doi.org/10.1016/j.proenv.2013.06.062

27. M. Stefano, A. Bernasconi, B. Bauder, et al., "Chemical and biological gradients along the Damma Glacier soil chronose (Switzerland), " Vadose Zone J. 10, 867883 (2011).

28. D. L. Strayer, R. E. Beighley, L. C. Thompson, et al., "Effects of land cover on stream ecosystems: roles of empirical models and scaling issues," Ecosystems 6, 407-423 (2003). https://doi.org/10.1007/s10021-002-0170-0

29. G. C. Topp, J. L. Davis, and A. P. Annan, "Electromagnetic determination of soil water content: Measurements in coaxial transmission lines," Water Resour. Res. 16 (3), 574-582 (1980).

30. K. van Looy, J. Bouma, M. Herbst, et al., "Pedotransfer functions in Earth system science: challenges and perspectives," Rev. Geophys. 55, 1199-1256 (2017). https://doi.org/10.1002/2017RG000581

Translated by D. Konyushkov 